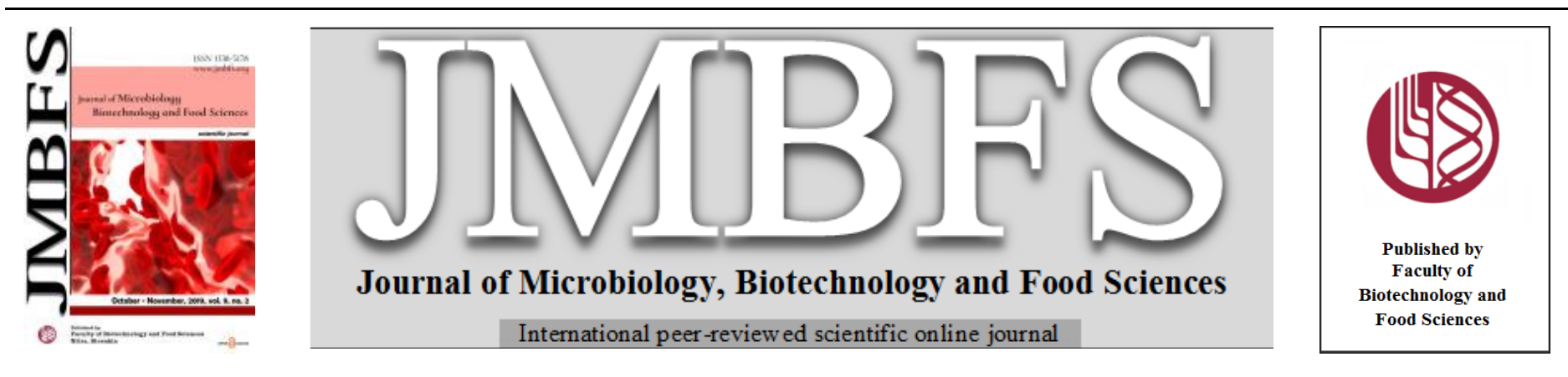

\title{
THERAPEUTIC APPLICATIONS OF BIOACTIVE COMPOUNDS OBTAINED BY ENDOPHYTIC Thielaviopsis basicola ISOLATED FROM Ximenia americana, WESTERN GHATS OF INDIA
}

\author{
Rohit Shankar Mane ${ }^{1}$, MK Anand ${ }^{2}$, Ankala Basappa Vedamurthy $*^{3}$ \\ $\operatorname{Address(es):~}$ \\ ${ }_{1,2,3}$ Department of Studies in Biotechnology and Microbiology, Karnatak University, Dharwad (KA) 580003, India. \\ ${ }^{1}$ Deaprtment of Life Sciences, Mandsaur University, Mandsaur, (MP), 458001, India. \\ ${ }^{2}$ C\&DST Laboratory, Department of Microbiology KIMS, Hubballi.
}

*Corresponding author: vedhamurthybt@gmail.com

doi: 10.15414/jmbfs.2020.9.5.870-878

ARTICLE INFO

Received 18. 5. 2018

Revised 21. 9. 2019

Accepted 17. 10. 2019

Published 1. 4. 2020

Regular article

OPEN $\partial_{\text {ACCESS }}$

\section{ABSTRACT}

The objective of the present study was the bioprospection of bioactive compounds from endophytic Thielaviopsis basicola with therapeutic applications, isolated from Ximenia americana, Western Ghats of Karnataka, India. The fresh and healthy leaves and roots of Ximenia americana were collected from the forests of Western Ghats of Karnataka, India. The collected explants were submerged for the enumeration and purification of fungal endophytes by using selective, and different media. Isolated fungal endophytes were processed for the production, extraction, phytochemical analysis, purification and evaluation of bioactive compounds by referring standard protocols. At a glance, endophyte derived bioactive compounds were used in in-vitro antagonistic, antioxidant antiurolithisis, and anticancer activity. A total of 32 pure isolates were obtained, 8 morphologically distinct fungal endophytes were identified from 200 explants of X. americana. Endophytic Thielaviopsis basicola was a core candidate identified and cultivated in solid-state fermentation on corn bran under the dark condition at $25^{\circ} \mathrm{C} \pm 2^{\circ} \mathrm{C}$ for 15 days. Obtained $5.30 \mathrm{~g}$ of aqueous crude extract per $100 \mathrm{~g}$ of cornmeal were processed for qualitative phytochemical analysis, in alkaloids, terpenoids, flavonoids, phenols, tannins, and glycosides were found. The aqueous crude extract showed $0.761 \mathrm{~g}$ of phenol and $0.276 \mathrm{~g}$ of flavonoids content. From these crude extract $\mathrm{TbCC} 1 \mathrm{and} \mathrm{TbCC} 2$, two fractions were purified by column chromatography and spotted potent bioactive compounds on thin layer chromatography. The FTIR data of $\mathrm{TbCC} 1$ and $\mathrm{TbCC} 2$ showed different functional groups such as alcohol, phenols, alkanes, alkenes, aromatic, alkyl halides, amines, ether, and nitrile. The TbCC1 exhibited prominent antagonistic activity and MIC against Staphylococcus aureus (24mm with $100 \mu \mathrm{g} / \mathrm{mL}$ ) and Candida albicans $(22 \mathrm{~mm}$ with $75 \mu \mathrm{g} / \mathrm{mL})$ while TbCC2 exhibited against Salmonella typhi $(22 \mathrm{~mm}$ with $75 \mu \mathrm{g} / \mathrm{mL})$ and Aspergillus fumigatus $(18 \mathrm{~mm}$ with $75 \mu \mathrm{g} / \mathrm{mL})$. The TbCC1 showed potent antioxidant activity $(86.24 \pm 0.35)$ with $5.26 \mu \mathrm{g} / \mathrm{mL}$ of IC50 value as compared with $\mathrm{TbCC} 2$. The maximum antiurolithiasis activity showed with $100 \%$ concentration at the rate of $67.5 \pm 1.49$ of aqueous crude extract. The Sulphorodamine B assay showed MCF7 human breast cancer cell line viability $98.39 \pm 0.0250$ at $100 \mu \mathrm{g}$ concentration and $40.81 \pm 0.0470$ at $500 \mu \mathrm{g}$ with an IC50 value of $459.60 \mu \mathrm{g}$. This is the first innovative report of endophytic Thielaviopsis basicola for their phytochemicals detection and prominent in-vitro activities from the selected plants.

Keywords: Endophytic Thielaviopsis basicola; microbial pathogens; kidney stone; MCF7 human breast cancer cell line; phytochemicals; Ximenia americana

\section{INTRODUCTION}

Nowadays there is a need to search novel bioactive compounds from natural sources because of the increased number of emerging diseases in the globe with their rapid development and spread of multidrug-resistant pathogens (Ananda $\boldsymbol{e t}$ al., 2010; Mane et al., 2017). Mostly novel antioxidant and anticancer bioactive compounds have to search from the natural entity. Somehow due to incomplete knowledge and unknown uses, many medicinal plants are lagging behind in the list of worldwide pharmaceutical research (Suryanarayanan et al., 2002; Aditi et al., 2017). The Indian research institutes such as National Chemical Laboratory, Department of Science and Technology and Department of Biotechnology has given high priority to the search for novel bioactive compounds to treat HIV, Tuberculosis, Kidney Stone, Cancer, and other microbial diseases (Padmanabhan et al., 1977; Julia et al., 2009; Dharmaraj et al., 2010). During the last decades, researchers revealed different bioactive compounds such as phenols (Fisher et al., 1991; Julia et al., 2009), flavonoids, tannins (Zeng et al., 1987), saponins, glycosides, terpenoids (Zhou et al., 2012; Zhang et al., 2013) etc. from the different fungal genera that possess a wide variety of biological activities including antifungal (Padmanabhan et al., 1977), antioxidant (Zhou et al., 2012), antimycobacterial (Zhang et al., 2013), antibacterial, and anticancer (Julia et al., 2009). Optionally, these all fungi are isolated and purified from different plant sources as endophytic fungi due to their ethnobotany and pharmaceutical applications (Sun et al., 2011; Sunayana et al.,
2014). In 1866, De Barry introduced the term "endophyte" for those microbes that reside inside the healthy tissues of plants without causing any apparent diseases (Romas et al., 2011). After 100 years, Carroll (1986) used the term 'endophyte' for those organisms that cause asymptomatic infections within the plants (Rodriguez et al., 2008; Li et al., 2008). Petrini elucidated Carroll's definition as commensalism in plants. Wilson further expanded endophytes and included both fungi and bacteria as commensals. Nowadays this term is expanded as endophytic microorganisms which include fungi and bacteria with actinomycetes, resides intracellularly for their whole or at least part of life cycle (Padmanabhan et al., 1977; Mane et al., 2017, 2018). In the present research study, Ximenia americana was selected as an effective plant candidate because of their unknown endophytic fungal diversity and bioactive compounds composition with in-vitro bioassay. The objectives of the present research study was 1 . Enumeration and Purification of fungal endophytes from Ximenia americana 2. Production, extraction, phytochemical analysis, purification and evaluation of endophyte derived bioactive compounds 3. In-vitro bioassy.

\section{MATERIAL AND METHODS}

Reagents and chemicals

All chemicals used in the present study were purchased from Sigma- Aldrich, USA and Hi-media, India. The chemicals like 2, 2-diphenyl-1-picrylhydrazyl 
(DPPH), Sulphorodamine B were purchased from Sigma- Aldrich, USA. 75\% ethanol, 4\% Sodium hypochlorite, Sodium azide, $250 \mathrm{~g}$ Potato dextrose agar medium, $250 \mathrm{~g}$ Potato dextrose broth, $250 \mathrm{~g}$ of Muller-Hinton agar medium Aluminum chloride, Potassium acetate, Folin-Ciocalteu reagent, 60-120 mesh silica gel, silica gel 60 F-254, Potassium bromide, TPVG were obtained from Himedia, India. Corn bran and other chemicals were obtained from local market.

\section{Isolation and characterization of endophytic fungi}

The fresh and healthy leaves and roots of Ximenia americana were collected from the forests of Karwar, Uttar Kannada district, Western Ghats of Karnataka, India in the month of July, 2018. The selection of plant Ximenia americana was based on ethnobotanical history and abundance. The plant were identified and authenticated by Dr. Kotresha K., at the Department of Botany, Karnatak Science College, Dharwad, Karnataka, India and a voucher specimen kept under the number N0-01/2018. All explants were immediately brought to the laboratory and processed for further work. The explants were washed under running tap water to remove the dust fond of to the surface and rinsed three times with distilled water. To eradicate the epiphytic microorganisms, the explants were surface sterilized according to the standard protocol ${ }^{19}$. Surface sterilized explants were dried on a sterile tissue paper and were cut with a sterile blade into 0.5 to $0.3 \mathrm{~cm}$ pieces; each piece was placed onto a Potato dextrose agar (PDA) plates. To avoid possible contamination, the final-rinse distilled water was placed on a fresh PDA plate as a negative control. All plates were incubated in dark at $25^{\circ} \mathrm{C} \pm$ $2^{\circ} \mathrm{C}$ for 15 days. When a mycelium appeared round the edge of the pieces on the PDA plates, the hyphal tips were transferred onto a freshly prepared PDA plates to obtain pure culture. Isolated endophytic fungi was subjected for the macroscopic and microscopic characterization such as the colour and nature of the growth of colony, morphology of fruiting structures and spore morphology by referring standard protocols ${ }^{6}$. The cultures were submitted to Mycology and Plant Pathology Group, Agharkar Research Institute, Pune, India for the identification and confirmation of endophytic fungi.

\section{Analysis of Data}

\section{Isolation Frequency}

The isolation frequency of emerging hyphae was determined for each of the explants.

$\mathrm{IF}=$

Number of explant pieces showing growth

Total number of explant pieces

Mean

The mean of isolated endophytic fungi was carried out by using following formula.

Where,

$$
\mathrm{X}=\Sigma \mathrm{X} / \mathrm{N}
$$

$\mathrm{X}=$ Mean

$\Sigma \mathrm{X}=$ the sum of total numbers in a list

$\mathrm{N}=$ the number of items in that list.

\section{Production, extraction, and phytochemical analysis}

The production of bioactive compounds was carried out by solid state fermentation in which corn bran was used as a substrate. Three pieces of the grown pure culture of Thielaviopsis basicola were cut from the culture plate and inoculated in a $1000 \mathrm{ml}$ Erlenmeyer flask containing $200 \mathrm{~g}$ of corn bran and 50 $\mathrm{ml}$ of distilled water and incubated in the dark at $25^{\circ} \mathrm{C} \pm 2^{\circ} \mathrm{C}$ for 15 days at static condition. At the end of the incubation period, the fermented media were processed for the extraction of bioactive compounds. Thielaviopsis basicola feremented media was submerged for the extraction of bioactive compounds in Soxhlet apparatus by using distilled water as a solvent. In brief, $100 \mathrm{ml}$ of distilled water was added in fermented media and kept on the rotary shaker for 24 hrs. After 24 hrs the mycelium and culture media were separated from each other by vacuum filtration. In the first hand, the filtrate was extracted three times with equal volume of distilled water as solvents for the complete extraction of metabolites from fungal biomass for $18-20$ hours at $40^{\circ} \mathrm{C}$ in Soxhlet apparatus. Then the concentration of extract was performed on Rota evaporator and dried under oven at $40^{\circ} \mathrm{C}$, weighed and stored at $15^{\circ} \mathrm{C}$. In another hand, obtained mycelium was air dried, weighed and recorded as $\mathrm{mg} / 100 \mathrm{~mL}$. Qualitative and quantitative phytochemical analysis of aqueous crude extract of Thielaviopsis basicola was employed for the detection of alkaloids, terpenoids, steroids, tannins, saponins, flavonoids, and phenols, coumarins, quinones and glycosides by preferring standard protocols. Quantification was done on the basis of the standard curve of gallic acid and results were expressed as gallic acid equivalent.
Column chromatography, thin layer chromatography, and Fourier transform infrared spectroscopy

Endophyte derived crude extract was run on 60-120 mesh silica gel (Spectrochem India) in column chromatography. A clean, dried glass column was filled with the silica gel slurry and petroleum ether filled up to of $20 \mathrm{~cm}$. The column was repeatedly washed and flushed with petroleum ether to set the bed of the silica gel in the column. The extract was dissolved in DMSO to obtain free flowing powder. Then the powder was loaded in the silica gel column through funnel and elution was started with petroleum ether. Each fraction was collected, named as $\mathrm{TbCC}$ and further used for structure elucidation. Thin Layer Chromatography (TLC) was performed by using precoated TLC plates with silica gel 60 F-254 for the investigation of bioactive compounds from the $\mathrm{TbCC} 1$ and $\mathrm{TbCC} 2$ using different solvent systems.

For alkaloids Methanol: conc. $\mathrm{NH}_{4} \mathrm{OH}(17: 3)$

For flavonoids Chloroform: methanol (18:2)

For terpenoids Benzene: Ethyl acetate (1:1)

For saponins Chloroform: glacial acetic acid: methanol: water $(6: 2: 1: 1)$

TLC plates were spotted with TbCC1 and TbCC2 obtained samples with standard solutions of alkaloids, flavonoids, terpenoids and saponins, and then developed in their respective eluent solvent systems. Chromatogram was developed in the closed TLC chamber in selected solvent system for 5 minutes. After 5 minutes, plates air dried and observed under sun light and UV light $(254$ and $366 \mathrm{~nm})$ for the observation of compound bands. Retention factor (Rf) value was calculated by using the following formula,

$\mathrm{Rf}=\mathrm{A} / \mathrm{B}$

Where,

observed spot.

$\mathrm{A}=$ distance between sample spot and central point of

front.

$\mathrm{B}=$ distance between the sample spot and the mobile phase

FTIR was used for the detection of the different functional groups present in the $\mathrm{TbCC} 1$ and $\mathrm{TbCC} 2$. The FTIR was handled by the diffuse reflectance technique in which the dried fraction sample was assorted with potassium bromide to form a very well powder and then compressed into a thin pellet. The pellet was used for the analysis of different functional groups. The samples were irradiated by a broad spectrum of infra red light and the stage of absorbance at a meticulous incidence was plotted after. The absorbance was measured between 400-600 nm for the identification and quantification of functional groups.

\section{In-vitro Bioassays}

\section{Antagonistic activity}

The two fractions $\mathrm{TbCC} 1$ and $\mathrm{TbCC} 2$ of Thielaviopsis basicola were used for invitro antagonistic activity against bacteria includes Staphylococcus aureus, Pseudomonas aeruginosa, Bacillus subtilis, Escherichia coli, Salmonella typhi and fungi include Candida albicans, Aspergillus flavus, Aspergillus niger, and Aspergillus fumigatus by well diffusion assay. In the well diffusion assay, the bacterium and fungal inoculum was prepared to the concentration of $1.0 \times 10^{4}$ $\mathrm{CFU} / \mathrm{ml}$ adjusted with saline. The culture suspension was prepared and used as a stock culture for the experiment purpose. The culture suspension was spreaded on nutrient agar medium for verification of other microbial contamination. Fluconazole and Telithromycin $(10 \mathrm{mg} / \mathrm{mL})$ were used as positive control and solvent DMSO was used as negative control. The verified microbial culture suspensions were spreaded on Muller-Hinton agar medium plates and purified extract samples were added in the wells with standard antibiotics. Plates were incubated at $37^{\circ} \mathrm{C}$ for $24 \mathrm{hrs}$ or $72 \mathrm{hrs}$ and zone of inhibition was recorded with the help of zone reader. All experiments were performed in triplicates. For the determination of MIC of TbCC1 and $\mathrm{TbCC} 2$ fractions broth micro dilution technique was used in 96- well microtitre plate. The microbial suspensions was adjusted at the concentration of $1.0 \times 10^{-4} \mathrm{CFU} / \mathrm{ml}[\mathrm{OD}=0.34]$. The different concentrations of $\mathrm{TbCC} 1$ and $\mathrm{TbCC} 2[25 \mu \mathrm{g} / \mathrm{mL}, \quad 50 \mu \mathrm{g} / \mathrm{mL}, \quad 75 \mu \mathrm{g} / \mathrm{mL}$, $100 \mu \mathrm{g} / \mathrm{mL}$, and $125 \mu \mathrm{g} / \mathrm{mL}$ ] was prepared and added in 96- well microtitre plate containing microbial suspensions. Telithromycin $(10 \mu \mathrm{g} / \mathrm{mL})$ were used as positive control and solvent DMSO was used as negative control. The plates were incubated at $37^{\circ} \mathrm{C}$ for $48 \mathrm{hrs}$ and absorbance was recorded at $630 \mathrm{~nm}$ in UVvisible spectrophotometer. IC50 was expressed as the concentration of $\mathrm{TbCC} 1$ and $\mathrm{TbCC} 2[\mathrm{mg} / \mathrm{ml}]$ essential to produce $50 \%$ reduction of microbial culture growth.

\section{Antioxidant activity}

Antioxidant was performed by ferric ion reducing power assay and DPPH radical scavenging Assay. The TbCC1 and $\mathrm{TbCC} 2$ fractions of Thielaviopsis basicola were pipette in different concentrations ranging from $100 \mu \mathrm{l}$ to $500 \mu \mathrm{l}$ were mixed with $2.5 \mathrm{ml}$ of $20 \mathrm{mM}$ phosphate buffer and $2.5 \mathrm{ml}(1 \% \mathrm{w} / \mathrm{v})$ potassium 
ferricyanide, and then the mixture was incubated at $40^{\circ} \mathrm{C}$ for $20 \mathrm{~min}$. To this mixture $2.5 \mathrm{ml}$ of $(10 \% \mathrm{w} / \mathrm{v})$ trichloroacetic acid and $0.5 \mathrm{ml}$ of $(0.1 \% \mathrm{w} / \mathrm{v})$ ferric chloride were added to the mixture and kept for $10 \mathrm{~min}$ at room temperature to produce green colored complex. Ascorbic acid was used as positive reference standard. The absorbance of the color developed was measured at $700 \mathrm{~nm}$ using UV-Vis spectrophotometer. The DPPH (2, 2 Diphenyl- 2- Picryl Hydrazyl) radical scavenging assay was carried out with $\mathrm{TbCC} 1$ and $\mathrm{TbCC} 2$ fractions of Thielaviopsis basicola according to the method proposed by ${ }^{24}$. About $100 \mu \mathrm{l}$ of a DPPH solution in prepared in ethanol $(60 \mu \mathrm{mol} / 1)$ was mixed with $100 \mu \mathrm{l}$ of the test samples in various concentrations. The blend was incubated for half an hour in dark at room temperature and the resultant absorbance was measured at 517 $\mathrm{nm}$. Ascorbic acid was used as a standard. The DPPH scavenging activity of each sample was calculated using the following equation:

DPPH scavenging activity $(\%)=\mathrm{A}_{\mathrm{c}}-\mathrm{A}_{\mathrm{t}} / \mathrm{A}_{\mathrm{c}} \times 100$

Where,

Ac $=$ the absorbance of the control reaction $(100 \mu$ of ethanol with $100 \mu \mathrm{l}$ of the DPPH solution).

$\mathrm{At}=$ the absorbance of the test sample.

\section{Antiurolithiasis activity}

Antiurolithisis activity was performed for the inhibition of oxalate crystals because of its satisfactory results simplicity and reproducibility in order to study inhibitory capacity of fractions. The solutions of $\mathrm{CaCl}_{2} \cdot 2 \mathrm{H}_{2} \mathrm{O}(9 \mathrm{mM})$ and $\mathrm{Na}_{2} \mathrm{C}_{2} \mathrm{O}_{4}(3 \mathrm{mM})$ were prepared using a buffer containing $0.15 \mathrm{M} \mathrm{NaCl}$ and 0.05 $\mathrm{M}$ Tris $\mathrm{HCl}$ at $\mathrm{pH}$ 6.5. The inhibitory solution was prepared by adding $0.25 \mathrm{ml}$ of fractions in $100 \mathrm{~mL}$ of $0.15 \mathrm{M} \mathrm{NaCl}$ solution. $1 \mathrm{~mL}$ of $\mathrm{CaCl}_{2}$ solution was assorted with $1 \mathrm{~mL}$ of inhibitory solution of fractions with different concentration $(25 \%, 50 \%, 75 \%, 100 \%)$. Blank reading were reported and sodium oxalate (1 $\mathrm{mL}$ ) was added. The absorbance was measured at $620 \mathrm{~nm}$ with the help of UV spectrophotometer at different time intervals.

\section{Anticancer activity}

The cells were dissociated with TPVG solution (0.2\% trypsin, $0.02 \%$ EDTA, $0.05 \%$ glucose in PBS). The stock cultures were grown-up in $25 \mathrm{~cm}^{2}$ culture flasks and every experiment were performed in 96 microtitre plates. For Cytotoxic activity, all weighed test drugs were disjointedly dissolved in DMSO and volume was completed up with DMEM supplemented with $2 \%$ inactivated FBS to obtain a stock solution of $1 \mathrm{mg} / \mathrm{ml}$ concentration and sterilized by filtration. Serial two fold dilutions were organized from this for carrying out cytotoxic studies. Anticancer activity of TbCC1 and TbCC2 of Thielaviopsis basicola was performed by using Sulphorodamine B (SRB) assay on MCF7 human breast cancer cell line at Rakesh Clinical Laboratory, Jath Maharashtra, India.

\section{RESULTS}

\section{Isolation of fungal endophytes}

Ximenia americana was collected from the forests area of Karwar, Western Ghat of Karnataka, India. Total 32 fungal endophytes were isolated and enumerated from 100 pieces of 200 explants such as leaves, and roots of $X$. americana. Most of the endophytic fungi were belonging to Ascomycetes. The endophytic Thielaviopsis basicola found to be a core group with the colonization frequency of $63.20 \%$ and further were confirmed by $18 \mathrm{~S}$ rRNA sequencing (Mane et al., Unpublished data). The endophytic Aspergillus niger found to be second largest core group with colonization frequency of $41.60 \%$ followed by Fusarium oxysporum (38.33\%), Sterile mycelia (33.20\%), Pestalotiopsis inflexa (27.20\%), Nigrospora species (20\%), and Alternaria alternata $(15.30 \%)$. The colonization frequency of leaves explant piece was varied between 0 to $46.6 \%$ and roots explant piece were varied from $0 \%$ to $20 \%$. The leaves piece showed highes colonization frequency by Thielaviopsis basicola (46.6\%) and lowest colonization frequency by Phomopsis species $(0 \%)$ while the root piece showed highest colonization frequency by Phomopsis species $(20 \%)$ and lowes colonization frequency by Nigrospora species $(0 \%)$. Results are shown in Plate 1 , Figure 1, and Table 1 .

\section{Characterization of fungal endophytes}

\section{Fusarium oxysporum}

Fusarium oxysporum showed moderate radial growth with $46 \mathrm{~mm}$ diameter on Potato dextrose agar media after 15 days of incubation period under the dark condition at $25^{\circ} \mathrm{C} \pm 2^{\circ} \mathrm{C}$. They showed $0.9 \mathrm{~cm} /$ day diameter growth with white to pink or violet colored mycelium. They produce two types of conidia such as microconidia and macroconidia. Microconidia are hyaline, septate, and small with 0-3 $\mu \mathrm{m}$ size while macroconidia are hyaline, circular, look-alike heel, septate and small with 0-2 $\mu \mathrm{m}$ size. They showed 20-30 spores per microscopic field. Conidiogenous cells hyaline, enteroblastic in nature.

$$
\text { Isolation frequency }(\%)
$$

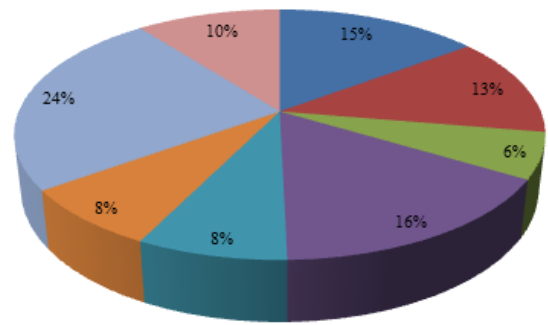

- Fiscaitumaxysporio - Sterile mycelia - Alternaria atemara - Asporgillus niger - Phomopsis species - Nigrospora species - Thielaviopsis becical - Pestalotiopsis inflexa

Figure 1 Isolation frequencies of fungal endophytes from Ximenia americana

Table 1 Isolation of fungal endophytes from Ximenia americana

\begin{tabular}{|c|c|c|c|c|c|c|}
\hline Endophytic fungi & Explants & Total Number of explant piece & Isolates & $\mathrm{IF}(\%)$ & Total & Mean \\
\hline \multirow[t]{2}{*}{ Fusarium oxysporum } & Leaves & 10 & 3 & 30.0 & \multirow[t]{2}{*}{38.33} & \multirow{17}{*}{32.35} \\
\hline & Roots & 12 & 1 & 8.33 & & \\
\hline \multirow[t]{2}{*}{ Sterile mycelia } & Leaves & 12 & 2 & 16.6 & \multirow[t]{2}{*}{33.20} & \\
\hline & Roots & 12 & 2 & 16.6 & & \\
\hline \multirow[t]{2}{*}{ Alternaria alternata } & Leaves & 13 & - & 0 & \multirow{2}{*}{15.30} & \\
\hline & Roots & 13 & 2 & 15.3 & & \\
\hline \multirow[t]{2}{*}{ Aspergillus niger } & Leaves & 12 & 3 & 25.0 & \multirow[t]{2}{*}{41.60} & \\
\hline & Roots & 12 & 2 & 16.6 & & \\
\hline \multirow[t]{2}{*}{ Phomopsis species } & Leaves & 15 & - & 0 & \multirow[t]{2}{*}{20.00} & \\
\hline & Roots & 10 & 2 & 20.0 & & \\
\hline \multirow[t]{2}{*}{ Nigrospora species } & Leaves & 15 & 3 & 20.0 & \multirow[t]{2}{*}{20.00} & \\
\hline & Roots & 14 & - & 0 & & \\
\hline \multirow[t]{2}{*}{ Thielaviopsis basicola } & Leaves & 15 & 7 & 46.6 & \multirow[t]{2}{*}{63.20} & \\
\hline & Roots & 12 & 2 & 16.6 & & \\
\hline \multirow[t]{2}{*}{ Pestalotiopsis inflexa } & Leaves & 11 & 3 & 27.2 & \multirow[t]{3}{*}{27.20} & \\
\hline & Roots & 12 & - & 0 & & \\
\hline Total & - & 200 & 32 & 16 & & \\
\hline
\end{tabular}



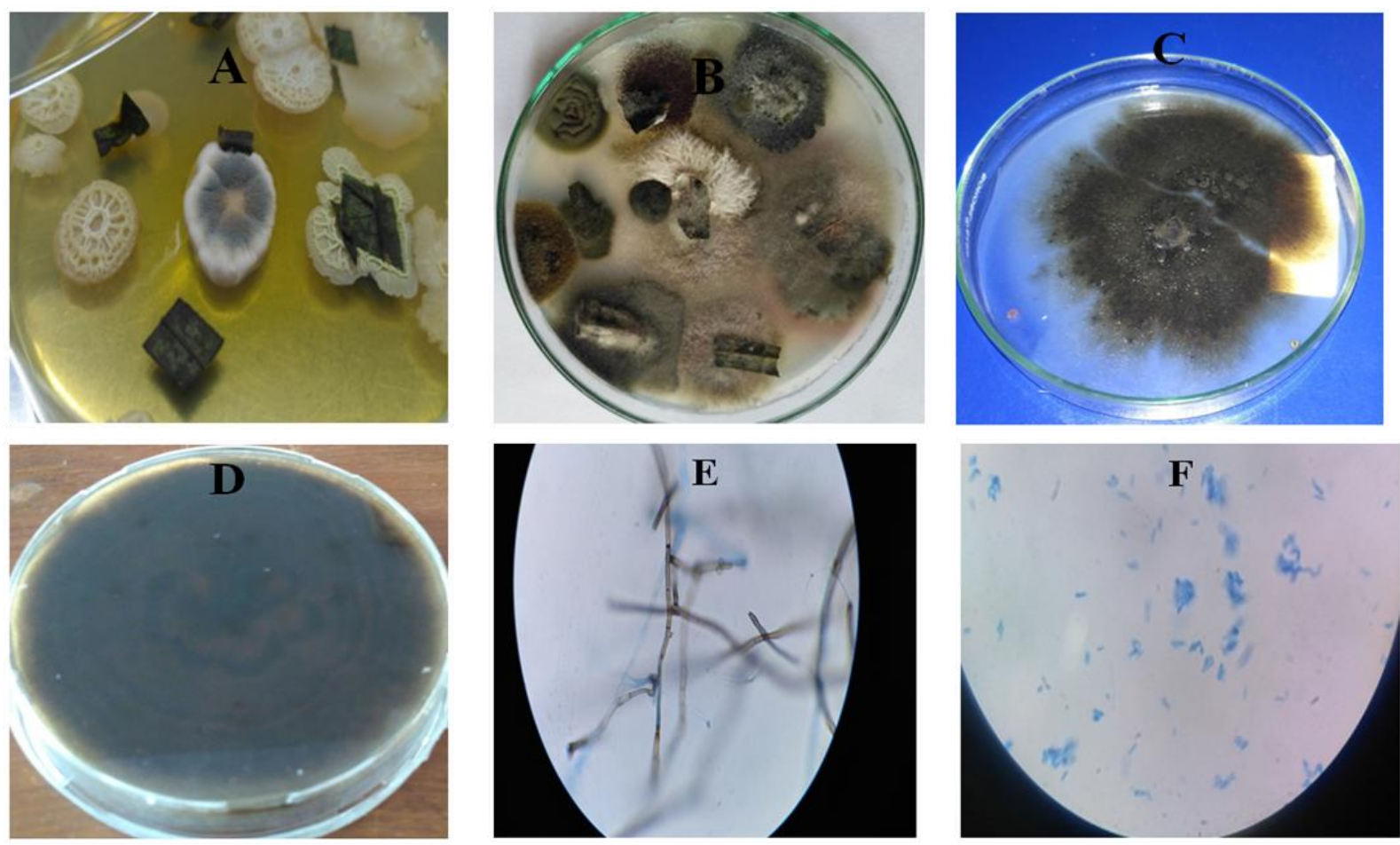

Plate 1 Isolation and characterization of fungal endophytes from leaves and roots of Ximenia americana (A) \& (B) Isolation of fungal endophytes on PDA medium plates in dark at $25^{\circ} \mathrm{C} \pm 2^{\circ} \mathrm{C}$ for 15 days (C) \& (D) Characterization and purification of Thielaviopsis basicola on PDA medium plates in the dark at $25^{\circ} \mathrm{C} \pm 2^{\circ} \mathrm{C}$ for 15 days, plates showing front and back side (E) \& (F) Microscopic characterization of mycelium and spores.

\section{Alternaria alternata}

Alternaria alternata showed good radial growth with $79 \mathrm{~mm}$ diameter on Potato dextrose agar media after 15 days of incubation period under the dark condition at $25^{\circ} \mathrm{C} \pm 2^{\circ} \mathrm{C}$. They showed $1.2 \mathrm{~cm} /$ day diameter growth with white color at start somehow changed into light brown with white mycelium after 10 days of incubation period. They showed pale brown colored conidiophores with 28.45 $\mu \mathrm{m}$. these conidia are oval in shape. They showed 10-16 spores per microscopic field.

\section{Aspergillus niger}

Aspergillus niger showed good radial growth with $76 \mathrm{~mm}$ diameter on Potato dextrose agar media after 15 days of incubation period under the dark condition at $25^{\circ} \mathrm{C} \pm 2{ }^{\circ} \mathrm{C}$. They showed $1.6 \mathrm{~cm} /$ day diameter growth with dark brown to black or purple colored mycelium. They produce two types of conidia such as microconidia and macroconidia. These conidiophores were raised from the substratum varying from $200 \mu \mathrm{m}$ to several millimeters long and 10- $20 \mu \mathrm{m}$ These were smooth, vesicle globose, phialides borne directly on the vesicles. They showed 30-42 spores per microscopic field.

\section{Phomopsis species}

Phomopsis species showed a slow growth because of sporulation nature. The colony of Phomopsis species looked dark in the form with mycelia being immersed, branched, septate and brown in color. The pycnidia are formed at the top of the mycelial mat, were globose in nature. After 10 days of incubation, the media become black because of secreted black pigment, therefore, the reverse side of the colonies was appeared black in color. They showed 8-12 spores per microscopic field.

\section{Nigrospora species}

Nigrospora species showed slow radial growth with $56 \mathrm{~mm}$ diameter. The colony was white at first then later it was observed as brown to black with more sporulation. They produced black and brown pigments on media due to which media were blackish in color. Conidiophores were branched, flexuous, colorless to brown, smooth in nature. They were black, shining, smooth unseptate 10-14 $\mu \mathrm{m}$ diameter. They showed 12-16 spores per microscopic field.

\section{Thielaviopsis basicola}

Thielaviopsis basicola showed good radial growth with $86 \mathrm{~mm}$ diameter. The colony of Phomopsis species looked dark all over the plate due to the production of black pigments. They produced two types of conidia namely endoconidia and aleuriospores. Endoconidia were single celled, hyaline, spores with rounded ends. They were arranged in the chain formate. They showed 3 to $5 \mu \mathrm{m}$ in diameter Aleuriospores were darkly pigmented in nature. They showed cylindrical spores that contain 2 to 6 cells and measures $20-25 \mu \mathrm{m}$ in length. Both showed nucleated septa. They showed 27-32 spores per microscopic field.

\section{Pestalotiopsis inflexa}

Pestalotiopsis inflexa showed moderate radial growth with $61 \mathrm{~mm}$ diameter on Potato dextrose agar media after 15 days of incubation period under the dark condition at $25^{\circ} \mathrm{C} \pm 2^{\circ} \mathrm{C}$. The colony of Phomopsis species looked light brown al over the plate. They showed conidia which were clavate to fusiform, rarely curved, smooth walled, straight 5-6 celled, 23-29 X 80-95 $\mu \mathrm{m}$. Apical and basal cell hyaline was long and broad cylindrical in nature. Septa were observed with the hardly constricted site. They showed 17-22 spores per microscopic field.

Production, extraction and phytochemical analysis of bioactive compounds

Solid state fermentation was employed for the production of bioactive compounds under static conditions by using $200 \mathrm{~g}$ of corn bran and $100 \mathrm{ml}$ of distilled water in the presence of Thielaviopsis basicola culture. After 15 days of incubation period, $100 \mathrm{ml}$ of aqueous solvent was added in the fermented media and then submerged for vacuum filtration. The filtrate and biomass were separated. The wet biomass of fungus was recorded as $2.86 \mathrm{~g} / 100 \mathrm{~g}$ of corn bran and the dried biomass recorded as $0.25 \mathrm{~g} / 100 \mathrm{~g}$ of corn bran. In another hand, obtained $80 \mathrm{ml}$ of filtrate were concentrated into $5.30 \mathrm{~g} / 100 \mathrm{ml}$ of the aqueous solvent by using Rota evaporator at $40^{\circ} \mathrm{C}$ after $6-8 \mathrm{hrs}$ rotation at $90 \mathrm{rpm}$ and used for further processes. The results are shown in figure 2 . The qualitative analysis of the aqueous crude extract of fungus revealed broad spectrum of secondary metabolites such as Phenols, Tannins, Flavonoids, Saponins, Alkaloids, and Glycosides. The quantitative analysis of the total phenolic content of the aqueous extract was estimated with Gallic acid as a reference standard. The extract showed high phenolic content $(23.0090 \pm 0.04129 \mathrm{mg})$. Total flavonoids content was performed using $\mathrm{AlCl}_{3}$ method using quercetin as a standard. The extract showed high flavonoids content $(53.47 \pm 0.88059 \mathrm{mg})$. The results were expressed as mg/g GAE per gram of endophytic extract. The results are shown in table 2 . 

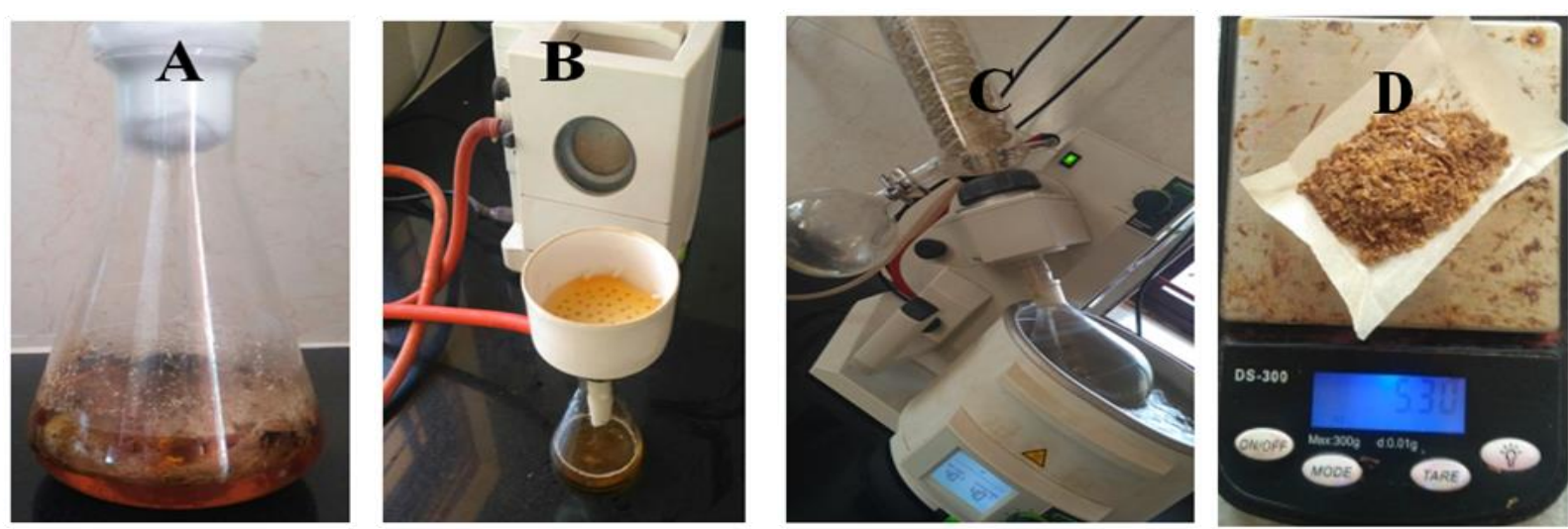

Figure 2 Fermentation and Extraction of bioactive compounds of aqueous crude extract obtained by the solid state fermentation from endophytic Thielaviopsis basicola (A) Fermented media (B) vacuum filtration to separate out fungal mycelium and extract (C) Rotary Evaporator for the concentration of aqueous crude extract (D) weighing.

Column chromatography, thin layer chromatography, and Fourier transform infrared spectroscopy

The column and thin layer chromatography were used for the purification of aqueous crude extract of the fungus. Total two fractions were purified from the column chromatography namely $\mathrm{TbCC} 1$ and $\mathrm{TbCC} 2$. Further, both fractions were implanted in thin layer chromatography for the detection of different bioactive compounds. TLC of TbCC1 and TbCC2 samples revealed the presence of fou compounds with different $\mathrm{R}_{\mathrm{f}}$ values such as alkaloids [0.29] in Methanol: conc. $\mathrm{NH}_{4} \mathrm{OH}-17: 3$, flavonoids [0.41] in Chloroform: methanol- 18:2, terpenoids [0.15] in Benzene: Ethyl acetate -1: 1, and saponins [0.91] in Chloroform: glacial acetic acid: methanol: water- 6:2:1:1 solvent systems. The results are shown in plate 2. The Fourier Transform Infrared Spectrophotometer analysis of TbCC1 and $\mathrm{TbCC} 2$ revealed different functional groups. The graph 1 and table 3 represents different functional groups of $\mathrm{TbCC} 1$. The very strong absorption bands observed at $3392.28 \mathrm{~cm}^{-1}$ which represents $\mathrm{O}-\mathrm{H}$ strong stretching vibrations It indicates alcohol and Phenols as a functional group. The very less absorption bands were observed at $605.83 \mathrm{~cm}^{-1}$ which represents $\mathrm{C}-\mathrm{Br}$ strong stretching vibrations. It indicates Alkyl halide as a functional group. The graph 2 and table 4 represents different functional groups of $\mathrm{TbCC} 2$. The very strong absorption bands were at $3745.33 \mathrm{~cm}^{-1}$ which represents $\mathrm{N}-\mathrm{H}$ strong stretching vibrations. It represents Amide groups. The very less absorption bands was at $458.24 \mathrm{~cm}^{-1}$ which represents C-I strong stretching vibrations. It indicates Alkyl halide functional group.

Table 2 Phytochemical analysis of the fungus aqueous crude extract (+ indicates presence and - indicates absence)

\begin{tabular}{c|c|c}
\hline Sr. No. & Tests & Observation \\
\hline 1 & Alkaloids & + \\
\hline 2 & Terpenoids & + \\
\hline 3 & Steroids & - \\
\hline 4 & Tannins & + \\
\hline 5 & Saponins & + \\
\hline 6 & Flavonoids & + \\
\hline 7 & Phenols & + \\
\hline 8 & Coumarins & - \\
\hline 9 & Quinones & - \\
\hline 10 & Glycosides & + \\
\hline
\end{tabular}

Table 3 FTIR frequencies of different functional groups with their intensities of $\mathrm{TbCC} 1$ obtained from crude aqueous extract of Thielaviopsis basicola.

\begin{tabular}{|c|c|c|c|}
\hline Functional Groups & Type of Vibration & Frequency & Intensity \\
\hline O-H Alcohol and Phenols & Stretch & 3392.28 & Strong \\
\hline -C-H Alkanes & Stretch & 2927.67 & Weak \\
\hline $\mathrm{C}=\mathrm{C}$ Alkenes & Stretch & 1633.50 & Weak \\
\hline -C-H Alkanes & Bending & 1460.21 & Medium \\
\hline $\mathrm{C}=\mathrm{C}$ Aromatic groups & Stretch & 1407.08 & Weak \\
\hline C-F Alkyl halide & Stretch & 1156.03 & Strong \\
\hline C-N Amine & Stretch & 1082.20 & Strong \\
\hline C-O Ether & Stretch & 1045.20 & Strong \\
\hline$=\mathrm{C}-\mathrm{H}$ Alkene & bending & 929.64 & Strong \\
\hline$=\mathrm{C}-\mathrm{H}$ Alkene & Bending & 887.45 & Strong \\
\hline C-Cl Alkyl halide & Stretch & 769.16 & Strong \\
\hline C-Cl Alkyl halide & Stretch & 710.09 & Strong \\
\hline C-Br Alkyl halide & Stretch & 605.83 & Strong \\
\hline
\end{tabular}

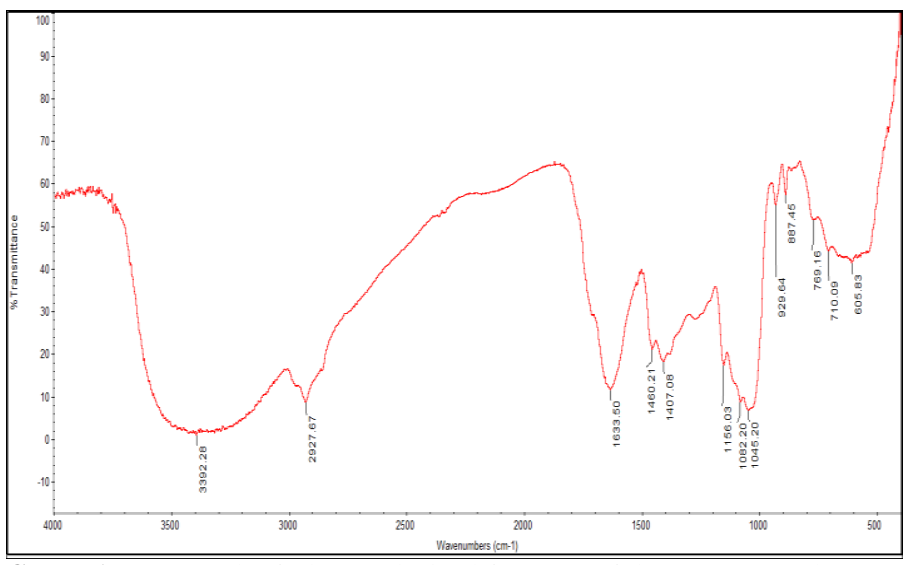

Graph 1 FTIR graph of TbCC1 obtained from CC of the aqueous crude extract of Thielaviopsis basicola

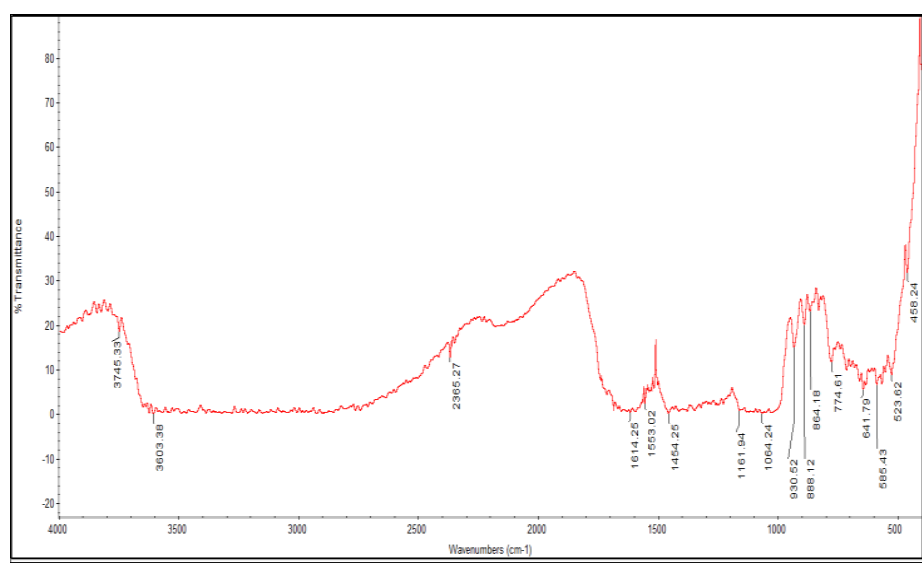

Graph 2 FTIR graph of TbCC2 obtained from $\mathrm{CC}$ of the aqueous crude extract of Thielaviopsis basicola. 
Table 4 FTIR frequencies of different functional groups with their intensities of TbCC2 obtained from crude aqueous extract of Thielaviopsis basicola.

\begin{tabular}{|c|c|c|c|}
\hline Functional Groups & Type of Vibration & Frequency & Intensity \\
\hline N-H Amide & Stretch & 3745.33 & Strong \\
\hline OH Alcohol and Phenols & Stretch & 3603.38 & Strong \\
\hline $\mathrm{C} \equiv \mathrm{N}$ Nitrile & Stretch & 2365.27 & Medium \\
\hline $\mathrm{C}=\mathrm{C}$ Aromatic groups & Stretch & 1553.02 & Weak \\
\hline $\mathrm{C}=\mathrm{C}$ Aromatic groups & Stretch & 1454.25 & Strong \\
\hline$=\mathrm{C}-\mathrm{H}$ Alkene & Bending & 930.52 & Strong \\
\hline$=\mathrm{C}-\mathrm{H}$ Alkene & Bending & 888.12 & Strong \\
\hline$=\mathrm{C}-\mathrm{H}$ Alkene & Bending & 864.18 & Strong \\
\hline$=\mathrm{C}-\mathrm{H}$ Alkene & Bending & 774.61 & Strong \\
\hline C-Cl Alkyl halide & Stretch & 641.79 & Strong \\
\hline C-Br Alkyl halide & Stretch & 585.43 & Strong \\
\hline
\end{tabular}

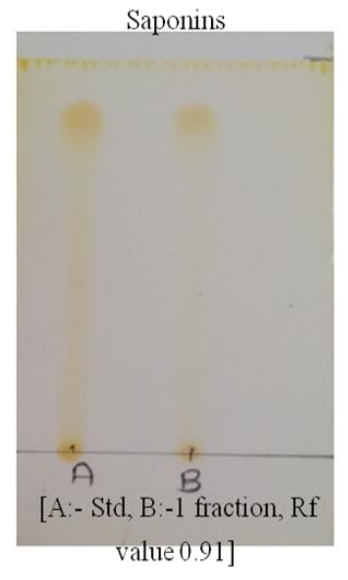

Plate 2 Thin layer chromatography spots under normal light for the detection of bioactive compounds compared with standards.

\section{Bioassay}

\section{Antagonistic activity}

The antimicrobial activity of $\mathrm{TbCC} 1$ and $\mathrm{TbCC} 2$ were performed against Staphylococcus aureus, Pseudomonas aeruginosa, Bacillus subtilis, Escherichia
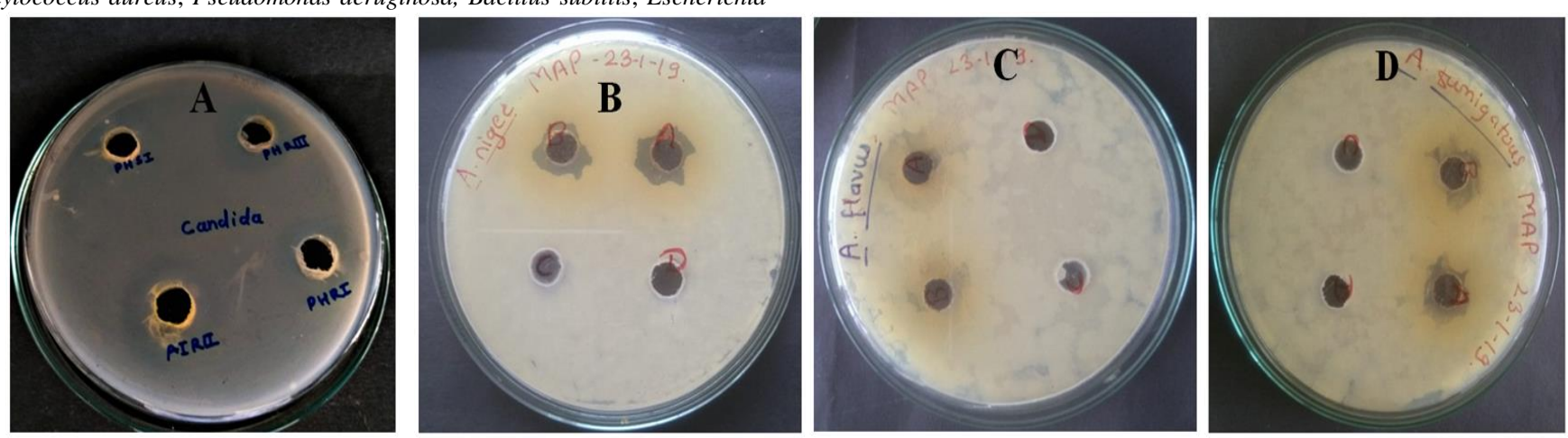

coli, Salmonella typhi, and fungi include Candida albicans, Aspergillus flavus, Aspergillus niger, and Aspergillus fumigatus by agar well diffusion method. The results of antimicrobial activity of TbCC1 and TbCC2 of Thielaviopsis basicola were summarized in Plate 3 and Table 7 . The results proved that the minimum inhibitory concentration value of $\mathrm{TbCC} 1$ and $\mathrm{TbCC} 2$ against selected microorganisms was varied and this inconsistency depends upon the microbia strains. The MIC values of TbCC1 against bacteria were $100 \mu \mathrm{g} / \mathrm{ml}$ (Staphylococcus aureus), $75 \mu \mathrm{g} / \mathrm{ml}$ (Pseudomonas aeruginosa), $100 \mu \mathrm{g} / \mathrm{ml}$ (Bacillus subtilis), $75 \mu \mathrm{g} / \mathrm{ml}$ (Escherichia coli), and $50 \mu \mathrm{g} / \mathrm{ml}$ (Salmonella typhi) while against fungi were $75 \mu \mathrm{g} / \mathrm{ml}$ (Candida albicans), $100 \mu \mathrm{g} / \mathrm{ml}$ (Aspergillus flavus), $100 \mu \mathrm{g} / \mathrm{ml}$ (Aspergillus niger), and $100 \mu \mathrm{g} / \mathrm{ml}$ (Aspergillus fumigatus). The results are shown in figure 4. The MIC values of TbCC2 against bacteria were $75 \mu \mathrm{g} / \mathrm{ml}$ (Staphylococcus aureus), $100 \mu \mathrm{g} / \mathrm{ml}$ (Pseudomonas aeruginosa), $75 \mu \mathrm{g} / \mathrm{ml}$ (Bacillus subtilis), $100 \mu \mathrm{g} / \mathrm{ml}$ (Escherichia coli), and $75 \mu \mathrm{g} / \mathrm{ml}$ (Salmonella typhi) while against fungi were $125 \mu \mathrm{g} / \mathrm{ml}$ (Candida albicans), 75 $\mu \mathrm{g} / \mathrm{ml}$ (Aspergillus flavus), $100 \mu \mathrm{g} / \mathrm{ml}$ (Aspergillus niger), and $75 \mu \mathrm{g} / \mathrm{ml}$ (Aspergillus fumigatus).

\section{Antioxidant activity}

Ferric ion reducing power assay was performed with TbCC1 and TbCC2 by using ascorbic acid as standard. In this assay, the highest antioxidant activity at the rate of $1.2407 \pm 0.00702$ showed by TbCC1 as compared to TbCC2. DPPH (2 2 Diphenyl, 2- Picryl Hydrazyl) assay was performed with TbCC1 and TbCC2 and ascorbic acid standard. Results of this assay showed potent antioxidant activity with TbCC1 being the highly potent $(86.24 \pm 0.35)$ as compared with TbCC2 $(82.5333 \pm 0.23714)$. The IC50 of TbCC1 found to be $5.26 \mu \mathrm{g} / \mathrm{mL}$ and TbCC2 found to be $7.24 \mu \mathrm{g} / \mathrm{mL}$.

Plate 3 Antifungal activities of TbCC1 and TbCC2 of Thielaviopsis basicola. The plates of Candida albicans (A), Aspergillus niger (B), Aspergillus flavus (C), and Aspergillus fumigatus (D). The wells A contain TbCC1 suspension, B contains TbCC 2 suspension, C contains DMSO and D contains Telithromycin. The all obtained pure cultures were spread on Muller Hinton agar and wells were prepared. Addition of all prepared suspensions, positive control, and negative control was done and incubated at $37^{\circ} \mathrm{C}$ for $72 \mathrm{hrs}$ and after 72 hrs zone of inhibition was recorded with the help of zone reader. 
Table 5 In vitro antagonistic activity of TbCC1 and TbCC2 of Thielaviopsis basicola. $[\mathrm{NA}]=$ Not Applicable, [-] = absence of zone of inhibition

\begin{tabular}{|c|c|c|c|c|c|c|c|c|c|c|}
\hline \multirow[t]{2}{*}{ Well No. } & \multirow{2}{*}{$\begin{array}{l}\text { CC Fractions and Standard } \\
\text { antibiotics }\end{array}$} & \multicolumn{9}{|c|}{ Zone of inhibition (mm) } \\
\hline & & 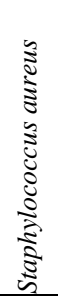 & 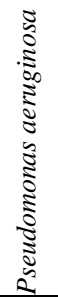 & 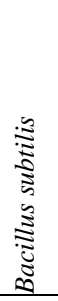 & 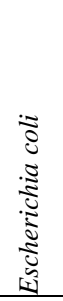 & 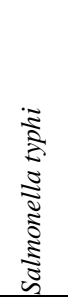 & 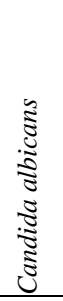 & 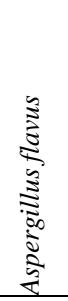 & 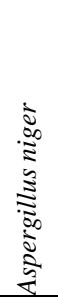 & 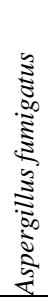 \\
\hline $\mathrm{A}$ & $\mathrm{TbCC} 1$ & 24 & 21 & 20 & 23 & 23 & 22 & 16 & 21 & 17 \\
\hline $\mathrm{B}$ & $\mathrm{TbCC} 2$ & 15 & 19 & 16 & 21 & 22 & 12 & 13 & 17 & 18 \\
\hline $\mathrm{C}$ & Telithromycin [Bacteria] & 28 & 24 & 22 & 25 & 23 & NA & NA & NA & $\mathrm{NA}$ \\
\hline $\mathrm{C}$ & Fluconazole [Fungi] & NA & NA & NA & $\mathrm{NA}$ & NA & 18 & 21 & 22 & 24 \\
\hline $\mathrm{D}$ & DMSO & - & - & - & - & - & - & - & - & - \\
\hline
\end{tabular}

\section{Antiurolithisis activity}

Antiurolithiasis activity of the fungus extract was effective against calcium oxalate crystals. The most effective concentration was at $100 \%$ with $67.5 \pm 1.49$ (Figure 3)

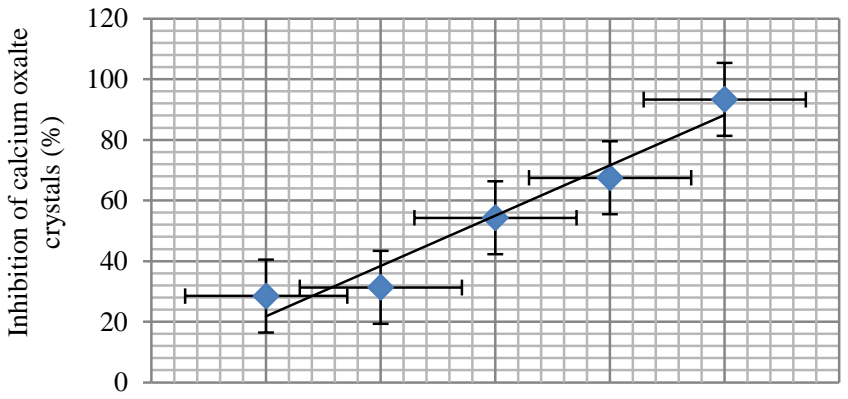

Different concentrations of obtained fractions

Figure 3 antiurolithiasis activity of the fungus

\section{Anticancer activity}

The TbCC1 and TbCC2 fractions were tested for their anticancer activity against MCF7 human breast cancer cell line by SRB assay. After completion of the protocol, the absorbance was recorded on an Elisa plate reader at a wavelength of $540 \mathrm{~nm}$. In detail, untreated MCF7 breast cancer cell lines taken as the control group, MCF7 breast cancer cell lines treated with standard drug Cisplatin considered as positive control group whereas $\mathrm{TbCC} 1$ and $\mathrm{TbCC} 2$ treated with MCF7 breast cancer cell lines taken as a treated group. The different concentration of the standard drug and TbCC1, TbCC2 $(200 \mu \mathrm{g}, 300 \mu \mathrm{g}, 400 \mu \mathrm{g}$, and $500 \mu \mathrm{g}$ ) were selected to learn morphological changes and cell growth inhibition of MCF7 breast cancer cell lines. Morphological studies revealed that significant increase in detached cells in the culture medium as compared with the control group treated group and positive control group. The normal cells showed regular and normal shape while treated MCF7 breast cancer cell lines were turgid and shrunken in shape. Morphological changes in nucleus representing apoptosis and also chromatin concentration, elongation of cells and reduction in cell count and density were observed which the features of apoptosis. Further, microscopic assessment exposed that morphological changes and decline of cells leading to cell apoptosis induced by the $\mathrm{TbCC} 1$. At the $100 \mu \mathrm{g}$ concentration of $\mathrm{TbCC} 1$ cell viability was $98.39 \pm 0.0250$ and at the $500 \mu \mathrm{g}$ concentration cell viability was $40.81 \pm 0.0470$, therefore, this clearly indicates that cells were alive at a minimum concentration only while they decreased their viability as the concentration of TbCC1 increased.

Table 6 Comparison of Effect of TbCC1 and Standard Drug Cisplatin on MCF7 breast cancer cell lines viability.

\begin{tabular}{|c|c|c|c|c|}
\hline Sr. No & Sample & Concentration $(\mu \mathrm{g})$ & Cell Viability (\%) & $\mathrm{IC}_{50}(\mu \mathrm{g})$ \\
\hline 1 & \multirow[t]{4}{*}{$\mathrm{TbCC} 1$} & 100 & $98.39 \pm 0.0250$ & \multirow[t]{4}{*}{459.60} \\
\hline 2 & & 200 & $84.75 \pm 0.0235$ & \\
\hline 3 & & 300 & $77.98 \pm 0.0020$ & \\
\hline 5 & & 500 & $40.81 \pm 0.0470$ & \\
\hline 6 & Cisplatin Std Drug & 30 & $43.39 \pm 0.0065$ & 20.0 \\
\hline
\end{tabular}

\section{DISCUSSION}

Karwar was selected as a study area because of great diversity of medicinal plants and unusual habitats with distinctive ecological environmental niche, novel strategies for survival, ethnobotanical antiquity. It lies in the hilly region of Western Ghats of Karnataka, India and situated on the rows of the Kali River. It is a coastal city on the west coast of the Indian isthmus, located at $14.820^{\circ} \mathrm{N}$ and $74.135^{\circ} \mathrm{E}$. It has a warm summer from March to May where the temperature may reach $37^{\circ} \mathrm{C}$. Winter from December to February is actual slight $\left(24^{\circ} \mathrm{C}\right.$ and $\left.32^{\circ} \mathrm{C}\right)$. The wind period from June to September has a usual rainfall of over 400 centimeters (160 in) and wind speed ranges from 1.2 to $2.5 \mathrm{~m} / \mathrm{sec}$ (Suryanarayanan et al., 2000; Mane et al., 2018). The plant selection from Karwar area was tough job therefore we used non-apparent hypothesis which deals with only herbs and harvests low molecular weight organic compounds with low toxicity and high bioactivity (Zhou et al., 2012; Zhang et al., 2013). It has been found that all plants seize fungal endophytes in their tissues of leaves, petioles, stems, twigs, bark, xylem, roots, fruits, flowers and seeds (Ananda et al., 2002; Dharmaraj et al., 2010; Aletaha et al., 2018). The plant tissues, especially leaves and roots are excellent reservoirs for endophytic fungi, isolated from up till uncharted areas and from extreme environment is the choice for development of potential novel metabolite. Due to their wide ethnobotany and pharmacology Ximenia americana was selected as an endophytic inhabiting candidate. Total of 32 fungal endophytes were isolated and most of them belonging to the classes Deuteromycetes, Ascomycetes, Zygomycetes and Basidiomycetes. Most dominant endophytic fungi was Thielaviopsis basicola at the rate of $46.6 \%$ and further were confirmed by 18S rRNA sequencing (Mane et al., Unpublished data). This result supports the findings of Khan et al., 2012; Mane et al., 2018 the fungal endophytes from Azadirachta indica, Terminalia arjuna, and Catharanthus roseus, belonging to Thielaviopsis Species and Aspergillus niger Rodriguez et al., 2008 studied endophytes from different medicinal plants and they were foliar endophytes. The colonization rate of fungal endophytes is significantly higher in the stems than in the leaves, but we found the opposite; nevertheless, the results of several previous studies were similar to ones obtained in the current study (Wilson et al., 1994). The probable reasons for these discrepancies are dissimilar organ arrangement, chemical composition, and even the period length of organs hang about residual in the tree, possibly leading to change in plant intracellular substance composition (Zeng et al., 1987). Even though a number of differences in endophytic fungi isolates were experiential between organs. In contrast with previous study samples, our samples were collected from the unusual area of India and therefore the diversity of the obtained isolates was high; nevertheless, we did not collect stem or flowers of Ximenia americana, therefore a few fungal endophytes may have been underrepresented. Previous reports of fungal endophytes from India may account for the high frequency from the roots of medicinal plants except for our results. There may be two reasons for the different enumeration count. One likely reason is the relationship between soil fungi and rhizospheric fungi. They have prevalent and diversified an endophytic relationship with the roots. The additional reason is that roots as significant sources of the easily nearby substrate may give a comparatively steady environment favoring much fungal continued existence (Zeng et al., 1987). In current years, there has been confirmed that the production of bioactive compounds by an endophyte is not accidental but seems to be 
correlated with his environmental niche. The metabolic communications of endophytes with its host may errand the synthesis of bioactive compounds. Fungal endophytes were isolated from grasses and further they showed the in vitro and in vivo production of different ergot alkaloids, loline alkaloids, lolitrems, growth hormone and paramine alkaloids (Rice et al., 1997). The endophytic fungi of grass grown in synthetic medium produced precursors of auxin in vitro while others showed production of Cryptocin by Cryptosporiopsis quercina with their potent activity against Pyricularia oryzae cavara and a number other plant pathogenic fungi. Merely Streptomyces was reported as a novel bioactive compounds producer from marine water. The bioactive compounds production may vary from organism to organism because of the substrate provided, metabolic processes, formation of products and byproducts, environmental conditions. Specific bioactive compound requires specific substrate to make chemical body with respect to provided semi-natural conditions (Lodge et al., 1996). Solid state fermentation revealed total of the wet and dried biomass of fungus at the rate of $2.86 \mathrm{~g} / 100 \mathrm{~g}$ and $0.25 \mathrm{~g} / 100 \mathrm{~g}$ of the corn bran respectively with $5.30 \mathrm{~g} / 100 \mathrm{ml}$ of concentrated aqueous crude extract. The aqueous crude extract showed phytochemical analysis variation with the presence of phenols, tannins, terpenoids, flavonoids, saponins, alkaloids and glycosides with phenolic content $(23.0090 \pm 0.04129 \mathrm{mg})$ and flavonoids content $(53.47 \pm$ $0.88059 \mathrm{mg}$ ). Two fractions namely TbCC 1 and TbCC 2 of crude extract obtained from the fungus by column chromatography revealed which further revealed the presence of alkaloids, flavonoids, terpenoids, and saponins in the solvents MA $\mathrm{CM}, \mathrm{BE}, \mathrm{CGMW}$ respectively in thin layer chromatography. The Rf values matched with standards and confirmed the purification and efficiency of bioactive compounds. Further FTIR showed different functional groups those are mainly found in natural drugs. The results of TbCC1 revealed the differen stretching and bending of the alcohol and phenols, alkanes, alkenes, aromatic groups, alkyl halides, amines, and ether groups while the TbCC2 revealed the alcohol and phenols, alkanes, alkenes, aromatic groups, alkyl halides, amines, ether, and nitrile. Phenolic and flavonoids compounds mainly observed as an antibacterial agents while terpenoids and alkaloid; cardiac glycosides have been reported to possess antifungal and antiurolithiasis activity (Murthy et al., 2010 Torres et al., 2015) Till date no reports were available on bioactive compounds from endophytic Thielaviopsis basicola in urolithiasis hence this study revealed new approach for urolithiasis. Partial purified fractions showed effective antagonistic, antioxidant, antiurolthisis and anticancer activities under controlled conditions. An endophytic Thielaviopsis basicola has ability to produce various bioactive compounds which will be used for various human diseases so it would be reported as an organism of pharmaceutical importance. However, further studies will need to undertaken to reveal the chemical structure of bioactive compounds and their toxic profile.

\section{CONCLUSION}

The present study aimed at evaluating different therapeutic applications of purified aqeous extract from an endophytic Thielaviopsis basicola in order to withdraw biologically active compounds. In this view, we purified differen bioactive compounds as far as antagonistic, antioxidant, antiurolthisis and anticancer activities are concerned by using ecofriendly aqeous solvent by solid state fermentation. The obtained data may provide innovative information about the present topic which may helpful in the drug designing and development in future.

Acknowledgments: We are great full to Professor and Vice chancellor Dr. P. B. Gai, Karnatak University, Dharwad, for extended facilities.

\section{REFERENCES}

Aditi, M. R., Arjun, V. G., \& Gayathri, M. H., (2017). A Brief Review on Medicinal Plants from South India, Endophytes and their Antidiabetes Properties International Journal of Current Research Review, 9, 1-4. http://dx.doi.org/10.5943/IJCRR/1/4/5

Aletaha, R. S., Sinegani, A. A., \& Zafari, D. (2018). A survey on the endophytic fungi in the roots of Chenopodiaceae under different environmental conditions. Mycosphere, 9, 618-634. http://dx.doi.org/10.5943/mycosphere/9/4/1

Ananda, A. K., \& Shridhar, S. K. (2002). Diversity of endophytic fungi in the roots of mangrove species on west coast of India. Canadian Journal of Microbiology, 48, 871-878. http://dx.doi.org/10.1016/cjm.2013.04.045

Anisworth, G. C., Sparrow, F. K., \& Sussaan, A. S. (1973). The Fungi? Advanced Treaties, Taxonomic review with keys. Academic Press, 3, 401-412. No doi found.

Devi, N. N., Prabakaran, J. J., \& Wahab, F. (2012). Phytochemical analysis and enzyme analysis of endophytic fungi from Centella asiatica. Asian Journal of $\begin{array}{lll}\text { Tropical } & \text { Biomedicine, } & \text { S(3), }\end{array}$ http://dx.doi.org/10.5943/AJTB/2/3/2

Dharmaraj, S. (2010). Marine Streptomyces as a novel source of bioactive substances. World Journal of Microbiology and Biotechnology, 26, 2123-2139. http://dx.doi.org/10.1007/s11274-010-0415-6
Fisher, P. J., Petrini, O., \& Webster, J. (1991). Aquatic hyphomycetes and other fungi in living aquatic and terrestrial roots of Alnus glutinosa. Mycological Research, 95, 543-547. http://dx.doi.org/10.1016/S0953-7562(09)80066-X Jena, S. K., and Tayung, K. (2013). Endophytic fungal communities associated with two ethno-medicinal plants of Smilipal biosphere reserve, India and their antimicrobial prospective. Journal of Applied Pharmaceutical Science, 3, S7S12. http://dx.doi.org/10.7324/JAPS.2015.50923

Julia, K. PhD thesis. (2009). New Natural Products from Endophytic Fungi from Mangrove Plants- Structure Elucidation and Biological Screening. HeinrichHeine University. No doi found.

Kannan, V. R., Arun, K. G., \& Robert, A. A. (2015). Exploration of endophytic microorganisms from selected medicinal plants and their control potential to multi drug resistant pathogens. Journal of medicinal plant Studies. 3, 49-57. No doi found.

Khan, A. L., Hamayun, H. M., \& Kang, S. M. (2012). Endophytic fungal association via gibberellins and Indole acetic acid can improve plant growth under abiotistress: an example of paecilomyces formosus LHL10. BMC Microbiology, 12, 30-36. http://dx.doi.org/10.1186/1471-2180-12-3

Li, J., Zhao, J., \& Xu, L. (2008). Endophytic fungi from rhizomes of Paris polyphylla var. yunnanensis. World Journal of Microbiology and Biotechnology, 24, 733-737. http://dx.doi.org/10.5897/AJMR11.1411

Lodge, J. D., Fisher, P. J., \& Sutton, B. C. (1996). Endophytic fungi of Manilkara bidentate leaves in Puerto-Rico. Mycologia, 88, 733-738 http://dx.doi.org/10.1080/00275514.1996.12026710

Mahesh, B., Tejesvi, M. V., Nalini, M. S., Prakash, H. S., Kini, K. R., \& Subbiah, V. (2005). Endophytic mycoflora of inner bark of Azadirachta indica A. Juss Current Science, 88, 2-25. http://dx.doi.org/10.1007/s12088-011-0121-6

Mane, R. S., Shinde, M. B., Wagh, P. R., \& Malkar, H. M. (2017). Isolation of Endophytic microorganisms as a source of novel secondary metabolite producers against Tuberculosis. International Journal of Studies and Research Technology, 3, 1267-1269. http://dx.doi.org/10.21448/ijsm.482798

Mane, R. S., \& Choradiya, B. R. (2018). Studies on endophytic bacteria isolated from grass against dysentery causing Shigella species. International Journal of Chemistry Studies, 2(1), 30-32. No doi found.

Mane, R. S., Jagtap, P. R., \& Vyawahare, M. A. (2019). Production, purification and evaluation of different functional groups from endophytic Penicillium species derived bioactive compounds isolated from Aloe vera. International $\begin{array}{llll}\text { Journal of } & \text { Chemistry } & \text { Studies, } & 3(2),\end{array}$ http://dx.doi.org/10.11448/IJCS.123451

Mane, R. S., \& Vedamurthy, A. B. (2018). Brief review on fungal endophytes.

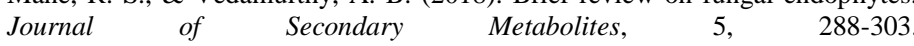
http://dx.doi.org/10.21448/ijsm.482798

Meshram, V., Kapoor, N., Chopra, G., \& Saxena, A. (2017). Muscodor camphora, a new record from Cinnamomum camphora. Mycosphere, 8, 568-582 http://dx.doi.org/10.5943/mycosphere/8/4/6

Murthy, N. K., Lakshman, H. C., \& Pushplatha, K. C. (2010). Biodiversity of endophytic fungi isolated from selected graminaceous hosts of Mercara region in Karnataka. International Journal of Plant Protection, 3, 335-341. No doi found. Oliveira, R. V., Souza, R. G., Lima, T. F., \& Cavalcanti, M. Q. (2014) Endophytic fungal diversity in coffee leaves (Coffee arabica) cultivated using organic and conventional crop management systems. Mycosphere, 5, 523-530. http://dx.doi.org/10.5943/mycosphere/5/4/4

Padmanabhan, P., \& Narayanaswamy, P. (1977). Growth studies of A. macrospora Zimm incitant of leaf spot disease of cotton. Madras Agricultural Journal, 64, 258-261. http://dx.doi.org/10.4172/2157-7471.S1-005

Rice, E. C., Miller, N., \& Paganga, G. (2010). Antioxidant properties of phenolic compounds. Trends in Plant Science, 2, 152-9. No doi found.

Rodriguez, R. J., White, J. F., \& Arnold, A. E. (2008). Fungal Endophytes: diversity and function area. Tansley review, 12, 1-17. http://dx.doi.org/10.1111/j.1469-8137.2009.02773

Romas, H.P., \& Said, S. (2011). Modulation of biological activities produced by an endophytic fungus under different culture conditions. Advances in biosciences and Biotechnology, 2, 443-449. http://dx.doi.org/10.1271/bbb.69.287

Suryanarayanan, T. S., \& Kumaresan, V. (2002). Endophytic assemblage in young, mature and senescent leaves of Rhizophora apiculate: evidence for the role of endophytes in mangrove community. Fungal diversity, 9, 81-91. No doi found.

Sun, Y., Wang, Q., Lu, X. D., Okane, I., \& Kakishima, M. (2011). Endophytic fungi associated with two Suaeda species growing in alkaline soil in China. Mycosphere, 2, 239-248. http://dx.doi.org/10.3389/fpls.2017.01767

Sunayana, N., Nalini, M. S., Sampath, K. K., \& Prakash, H. S. (2014). Diversity studies on the endophytic fungi of Vitex negundo L. Mycosphere, 5, 578-590. http://dx.doi.org/10.5943/mycosphere/5/4/10

Torres, J. O., \& Delacruz, T. E. (2015). Antibacterial activities of fungal endophytes associated with the Philippine endemic tree, Canarium ovatum. Mycosphere 6, 266-273. http://dx.doi.org/10.5943/mycosphere/6/3/4

Valeria, U., Maria, A. S., \& Piero, B. (2013). Survey of the ethnobotanical uses of Ximenia americana L. (mumpeke) among rural communities in South Angola. Journal of Medicinal Plants Research, 7, 7-18. http://dx.doi.org/10.5897/JMPR11.492 
Wink, M. (2015). Modes of action of Herbal medicines and plant secondary metabolites. Medicines, 2, 251-286. http://dx.doi.org/10.3390/medicines2030251

Wilson, D., \& Carroll, G. C. (1994). Infection studies of Discula quercina, an endophyte of Quercus garryana. Mycologia, 86, 635-647 http://dx.doi.org/10.2307/3760534

Zeng, D., He, Z., \& Fu, Y. (1987). Studies on biological control of oil tea anthracnose. Mycobiology, 23, 144-150. http://dx.doi.org/10.1080/12298093.2018.1454008

Zhang, L., Zhang, Y., \& Wang, S. (2013). The composition and diversity of endophytic fungi in different parts of Camellia oleifera Abel. Mycobiology 27, 101-105. http://dx.doi.org/10.1080/12298093.2018.1454009

Zhou, X., Zhang, T., \& Zhang, M. (2012). Isolation of endophytic fungi from Camellia oleifera. Journal of Anhui Agricultural Sciences, 40, 8958-8959. http://dx.doi.org/10.5943/mycosphere/6/8/12 